\title{
A importância da rapidez de atendimento em supermercados: um estudo de caso
}

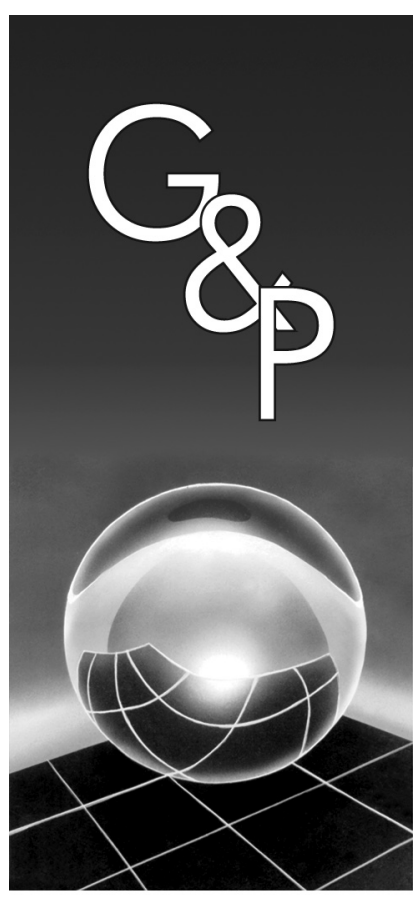

\author{
José Gilberto Spasiani Rinaldi \\ Reinaldo Morabito \\ Vilma Mayumi Tachibana
}

\begin{abstract}
Resumo
Neste trabalho, analisam-se algumas causas pelas quais clientes frequentam um supermercado, tais como: preço de produtos, localização do estabelecimento, rapidez de atendimento, qualidade de atendimento, variedade de produtos, estacionamento e outras. Por meio de análise estatística multivariada, foi verificada a relevância de cada causa em contraste com as outras, ou seja, a importância relativa de cada uma. Assim, pôde-se observar que a rapidez de atendimento desempenha um papel importante em relação às demais para o nível de serviço dos clientes. Utilizando-se análise de agrupamentos hierárquicos de variáveis e análise de correspondência, associaram-se causas em grupos e relacionaram-se causas a alguns fatores, como, por exemplo, escolaridade dos clientes, sendo esta uma observação interessante por existir, no Brasil, uma relação significativa entre renda e escolaridade. A coleta de dados foi realizada em um supermercado no interior de São Paulo e, desta forma, os resultados baseiam-se em um estudo de caso, tendo limitações inferenciais.
\end{abstract}

Palavras-chave: Supermercados. Rapidez de atendimento. Análise de agrupamentos. Análise de correspondência.

\section{Introdução}

Os supermercados são empresas varejistas, ou seja, representam o último elo da cadeia entre um produto e seu consumidor final, vendem proeminentemente alimentos perecíveis dispostos em formato para autoatendimento (self-service) e dispõem de caixas para pagamento (checkouts) na saída, tratando-se, portanto, de autoserviço. Estas empresas têm se preocupado em melhorar o nível de serviço ao consumidor para fidelizá-lo e aumentar o volume de vendas. Pode-se observar uma forte tendência de grandes redes de supermercados em fazer uso de tecnologias mais avançadas que permitam utilizar um menor número de empregados, maior número de caixas para atendimento, maior flexibilidade de horário, disposição organizada e maior variedade dos produtos.

A frequência ao estabelecimento faz com que o consumidor se acostume ao local, conhecendo melhor o espaço físico, a variedade encontrada e a disposição dos produtos, além de ter a percepção dos horários menos congestionados, facilitando suas compras. Desta maneira, o consumidor fica fidelizado ao supermercado onde realiza suas compras. Clientes podem escolher o local de suas compras por diversos fatores, como preço e variedade de produtos, localização do estabelecimento, rapidez de atendimento e funcionários educados e prestativos em atender, disponibilidade de estacionamento, entre outros. Gerentes de supermercados costumam apontar que preços altos e filas de espera exageradas são fatores que podem levar o estabelecimento a uma diminuição da frequência dos clientes e, consequentemente, a uma queda no volume de vendas. No tempo total de permanência do cliente no supermercado, um fator determinante pode ser o tempo de espera na fila do caixa.

Em meados da década passada, a consultora Price Waterhouse previu que em 2005 os supermercados não teriam mais operadores de caixas e carrinhos de compras, e os depósitos seriam operados por robôs que entregariam as compras já embaladas (BADIN, 1997). Na maioria dos supermercados isto não ocorreu, contudo, nos supermercados Winn Dixie (EUA), por exemplo, os caixas são automáticos (automatic checkouts), ficando o cliente responsável por todo o processo de passar os itens selecionados e pelo seu pagamento (GUERRA, 2006). O desafio de melhorar o atendimento em supermercados, reduzindo-se a espera em filas, não é um problema recente. Em 1996, segundo a consultora Nielsen (apud BNDES, 1996), os principais motivos apon- 
tados de queixas dos clientes em supermercados referiam-se a filas no caixa (56\%), supermercado lotado (41\%), falta de empacotador (35\%) e falta de preço nos produtos (25\%). Nota-se que todos estes motivos afetam o tempo de permanência do consumidor na fila.

Uma área de estudo que procura minimizar os efeitos da espera na fila é o gerenciamento das percepções nas filas de espera (COGAN, 1998). Em vários locais, técnicas aplicadas a esta área têm obtido resultados satisfatórios. Alguns estudos procuram relacionar a capacidade de serviço (ou atendimento) com o aumento da demanda (ITTIG, 2002). Assim, pode-se obter um tradeoff (compromisso, compensação) entre capacidade de atendimento e volume de vendas, auxiliando na tomada de decisões. Entender a motivação e o comportamento do consumidor frente a novas tecnologias em autoatendimento também tem sido objeto de pesquisa (DABHOLKAR et al., 2003). Fatores situacionais e características do consumidor foram estudados e concluiu-se que uma variável relevante para qualquer serviço é a espera (DABHOLKAR; BAGOZZI, 2002). Até mesmo esperar para baixar informação (download) pela Internet já preocupa gerentes em relação ao comportamento do usuário. Também, falhas e sucessos de compra pela Internet têm sido investigados para entender e predizer tecnologia em autoatendimento (BOBBITT; DABHOLKAR, 2001).

Percebe-se que a espera, de um modo geral, sensibiliza o cliente em seu futuro comportamento. Um consumidor insatisfeito com seu tempo de espera talvez possa não desistir de sua compra naquele momento, entretanto, pode não voltar mais àquele estabelecimento devido à imagem negativa percebida. Esta é uma perda difícil de ser quantificada e, se o problema permanecer durante um longo prazo o estabelecimento terá queda de demanda possivelmente sem descobrir a razão disto.

Um dos objetivos do presente estudo é avaliar se o tempo de espera na fila de caixas de supermercados desempenha um papel importante para o nível de serviço dos clientes, baseando-se em um estudo de caso. Outro é estudar as causas pelas quais o cliente frequenta um supermercado e, nestas, a relevância de cada uma em contraste com as outras, e sua importância relativa. Assim, pode-se contextualizar o cenário no qual os clientes enxergam a importância da fila e de seu tempo de espera. Associar a escolaridade do cliente a fatores pelos quais este frequenta o local é uma contribuição interessante para supermercados, pois, no Brasil, existe uma relação significativa entre renda e escolaridade. Conhecer sua clientela é desejo de qualquer empresa que quer fidelizá-la. Desta forma, esta questão também é pesquisada.

Com o objetivo de coletar informações relevantes sobre a sensibilidade do usuário em relação ao tempo na fila (RINALDI, 2007) e as causas pelas quais ele frequenta o supermercado, foi desenvolvido um questionário (survey) (REA; PARKER, 2000). Este foi aplicado utilizando-se amostragem sistemática na saída dos clientes após o atendi- mento no caixa. Para realizar a análise dos dados fornecidos pelos questionários, foram utilizadas técnicas estatísticas multivariadas, como intervalos de confiança simultâneos, análise de agrupamento hierárquico (com análise fatorial) e análise de correspondência. Estas técnicas permitem analisar o comportamento de várias variáveis simultaneamente e podem ser encontradas em detalhes em diversas referências como, por exemplo, Johnson e Wichern (2007), Aaker et al. (2004), Bartholomew et al. (2002), Carvalho (2004), Pereira (2004) e Hair et al. (2005). Convém salientar que não se tem conhecimento de outros trabalhos na literatura que aplicaram estas técnicas, particularmente análises de correspondência simples e múltipla, para analisar as causas pelas quais clientes frequentam um supermercado e relacioná-las a alguns fatores ou características dos clientes. Os instrumentos principais de pesquisa, então utilizados, foram constituídos de um questionário e do software estatístico Minitab.

A análise de agrupamentos (ou conglomerados - cluster analysis) difere de métodos de classificação, pois nestes últimos o número de grupos é conhecido. Esta análise não pressupõe um número nem uma estrutura de conglomerados, e toma como base similaridades (ou proximidades) entre itens (objetos, indivíduos ou variáveis), que podem ser de alguma forma medidas. Como resultado, obtém-se um certo número de conglomerados no qual se agrupam, devido a sua proximidade, os itens, inicialmente dispersos.

O termo correspondence analysis (análise de correspondência) deriva do francês analyse factorielle de correspondences, que é o termo usado por Jean-Paul Benzecri e outros que desenvolveram a técnica (BARTHOLOMEW et al., 2002). Contudo, a idéia básica é encontrada muito antes na tentativa de realizar escalas comparativas de categorias em tabelas de contingência. É usualmente empregada para estudar as relações entre variáveis, como também entre as categorias destas variáveis, representando suas proximidades em um sistema de projeção plana. Estas proximidades são descritas por distâncias projetadas em um plano e avaliadas segundo seu posicionamento, estabelecendo ou revelando possíveis associações. O plano resultante da análise é frequentemente denominado de mapa de percepções.

Este artigo está organizado da seguinte maneira: na seção 2, o processo de coleta de dados é descrito resumidamente e uma análise inicial das informações é apresentada, baseada em análise de intervalos de confiança simultâneos, para estudar a importância relativa de causas como preço e variedade de produtos, localização e estacionamento, rapidez e qualidade de atendimento, entre outras. Nas seções 3 e 4, são aplicadas, respectivamente, as técnicas de análise de agrupamentos (com análise fatorial) e análise de correspondência (simples e múltipla), com o objetivo de associar as causas em grupos e relacionar estas causas a alguns fatores, como escolaridade dos clientes, tamanhos das compras e percepção de diferenças de preços de produtos. Finalmente, 
na seção 5, são apresentadas as conclusões do trabalho e perspectivas para pesquisa futura.

\section{Coleta de dados e análise inicial das informações}

\subsection{Coleta de dados}

Elaborou-se um questionário (Anexo) com o intuito de comparar a importância de algumas características pelas quais clientes frequentam o supermercado. Uma questão principal solicita aos clientes que estabeleçam uma ordem de importância em relação às características de frequência ao supermercado, tais como: preços praticados, localização do estabelecimento, rapidez e qualidade de atendimento, variedade de produtos, estacionamento e outras. Foram também solicitadas informações a respeito de escolaridade dos clientes, número de itens comprados e ainda sua opinião sobre a existência de diferença significativa de preços entre estabelecimentos distintos.

Na Tabela 1, encontram-se discriminados os dias e horários de coleta, bem como a quantidade de questionários aplicados e o tempo médio de entrevista por questionário. A coleta de dados foi realizada em dias pré-determinados e no período de duas horas por dia por serem considerados (baseado na experiência dos gerentes e em dados do supermercado) períodos de grande fluxo e de clientes com perfil característico. Ao todo, foram 307 entrevistas das, quais 4 foram descartadas, referentes a pessoas sem escolaridade (entre parêntesis na tabela), pois estas demonstraram insegurança nas respostas fornecidas. Para os dias de coleta, os tempos médios por questionário denotam haver coesão e, assim sendo, podem-se considerar os dados como obtidos de uma amostragem sistemática. O questionário foi aplicado com a intenção de levantar características importantes para os clientes, ou seja, que estimulem ou mesmo determinem suas frequências ao local. Por outro lado, pretende também levantar possíveis problemas ou falhas que os clientes possam apontar em relação ao atendimento recebido. Estes problemas devem ser considerados como oportunidades na melhoria constante da qualidade de atendimento.
Apesar da riqueza de análise que todas estas informações trazem isoladamente, é ainda mais interessante analisá-las conjuntamente, ou seja, relacioná-las pode nos levar a descobertas úteis para um melhor gerenciamento da qualidade de atendimento. Um aspecto importante está na análise da primeira questão do questionário aplicado aos clientes. Os dados para esta questão foram alocados segundo a ordem com que o cliente manifestou sua preferência. Como exemplo, se um cliente colocou em primeira posição de preferência localização, em segunda, preço, em terceira, qualidade de atendimento e não apontou mais nenhuma outra, o preenchimento da planilha ficou: preço $=6$, localização $=7$, rapidez $=0$, qualidade $=5$, variedade $=0$, estacionamento $=0$, outros $=0$. Ou seja, 7 para a característica mais importante, 6 para a segunda, e assim consecutivamente (notar que há 7 alternativas), sendo 0 para as ausentes na resposta (que não são consideradas importantes para o consumidor).

\subsection{Análise de intervalos de confiança simultâneos}

A suposição de normalidade para testes de hipótese e regiões de confiança para um vetor de médias é de difícil constatação e poucas vezes verificada, mesmo para pequenas dimensões. Algumas alternativas podem ser conseguidas quando se possuem amostras relativamente grandes, contornando a necessidade de normalidade. Um resultado bastante útil é enunciado a seguir. Seja $\mathrm{x}_{1}, \mathrm{x}_{2}, \ldots, \mathrm{x}_{n}$ uma amostra aleatória de uma população com média $\mu$ e matriz de covariâncias positiva definida $\sum$. Seja $p$ o número de variáveis aleatórias. Se $n-p$ é grande, então o intervalo (Equação 1):

$$
\mathrm{a}^{\prime} \overline{\mathrm{X}} \pm \sqrt{\chi_{p}^{2}(\alpha)} \sqrt{\frac{\mathrm{a}^{\prime} \mathrm{Sa}}{n}}
$$

contém a' $\mu$, para todo $\mu$, aproximadamente com probabilidade $1-\alpha$, sendo a um vetor de constantes, $\overline{\mathrm{X}}$ o vetor de médias amostrais, $\mathrm{S}$ a matriz amostral de covariâncias e $\chi_{p}^{2}(\alpha)$ o valor crítico da distribuição Qui-Quadrado com $p$ graus de liberdade e nível de significância $\alpha$ (JOHNSON, WICHERN, 2007). Aqui admite-se que

Tabela 1. Informações gerais sobre a coleta de dados do experimento.

\begin{tabular}{cccc}
\hline Data & Horário & Questionários coletados & Tempo médio por questionário \\
\hline $03 / 12 / 2004$ & 18 horas às 20 horas & 55 & 2,18 minutos \\
$04 / 12 / 2004$ & 10 horas 30 minutos & 55 & 2,18 minutos \\
& às 12 horas 30 minutos & $47(1)$ & 2,50 minutos \\
$05 / 12 / 2004$ & 10 horas 30 minutos & $49(1)$ & 2,40 minutos \\
& às 12 horas 30 minutos & $47(2)$ & 2,45 minutos \\
$10 / 12 / 2004$ & 18 horas às 20 horas & & 2,40 minutos \\
$11 / 12 / 2004$ & 10 horas 30 minutos & 50 & \\
\hline
\end{tabular}


$\mathbf{a}^{\prime}=[0,0, \ldots, 1,0, \ldots, 0]$, colocando-se a constante 1 na posição adequada para o intervalo individual pretendido. Considerando-se os valores coletados na amostra para as variáveis preço, localização, rapidez, qualidade, variedade, estacionamento e outras, foram obtidos os intervalos de confiança simultâneos com nível de significância $\alpha=0,005$, conforme expressão (1), dados na Tabela 2.

Para comparar duas variáveis, como qualidade e rapidez, utiliza-se $\mathbf{a}^{\prime}=[0,0,-1,1,0,0,0]$ obtendo-se $\mathrm{a}^{\prime} \overline{\mathrm{X}} 1,18811$ e $\sqrt{\frac{\mathrm{a}^{\prime} \mathrm{Sa}}{n}}=0,18887$. A partir destes resultados, com $\alpha=0,005$, o intervalo de confiança é dado por [0,33755; 2,03867], que não contém o valor zero (representando a igualdade entre as variáveis). Desta forma, pode-se concluir que a variável qualidade de atendimento é considerada mais importante que rapidez de atendimento. Empregando-se o mesmo raciocínio, concluiu-se que qualidade de atendimento é mais importante que qualquer outra variável; rapidez de atendimento é equivalente à localização e mais importante que preço e variedade; localização, preço e variedade são equivalentes entre si; estacionamento e outras são equivalentes entre si, mas de menor importância que todas as outras variáveis.

Deve-se observar que, analisando-se a sobreposição dos intervalos de confiança individuais, na Tabela 2, chega-se às mesmas conclusões acima, tanto com $\alpha=0,005$ como com $\alpha=0,05$. Isto ocorre devido ao grande tamanho amostral considerado neste trabalho. Estes resultados ressaltam a consistência que esta análise traz quanto às características estudadas, indicando a importância de cada característica na frequência do cliente ao supermercado.

Resumindo, pelos intervalos de confiança, é interessante observar que apostar principalmente em preço, como é comum em supermercados, pode ser um engano para fidelização de clientes. Os clientes, pelo menos deste supermercado, buscam prioritariamente qualidade e rapidez de atendimento. A próxima técnica estatística empregada fornece informações sobre o perfil de conduta dos clientes, ou seja, explicita a relação de proximidade entre essas características conforme as respostas dos clientes.

Tabela 2. Intervalos de confiança simultâneos com $\alpha=0,005$.

\begin{tabular}{lcccc}
\hline \multicolumn{1}{c}{ Variável } & Média & $\mathbf{S}_{i i}$ & $\begin{array}{c}\text { Limite } \\
\text { inferior }\end{array}$ & $\begin{array}{c}\text { Limite } \\
\text { superior }\end{array}$ \\
\hline Preço & 2,41584 & 2,83521 & 1,98022 & 2,85146 \\
Localização & 3,03630 & 3,13314 & 2,57837 & 3,49424 \\
Rapidez & 3,35974 & 2,90112 & 2,91908 & 3,80039 \\
Qualidade & 4,54785 & 2,79134 & 4,11562 & 4,98009 \\
Variedade & 2,28713 & 2,73318 & 1,85942 & 2,71484 \\
Estacionamento & 0,21122 & 0,99748 & $-0,04716$ & 0,46961 \\
Outras & 0,56106 & 1,70568 & 0,22318 & 0,89894 \\
\hline
\end{tabular}

\section{Análise de agrupamentos e outras carac- terísticas dos clientes}

\subsection{Análise de agrupamentos hierárquicos}

Os procedimentos de agrupamentos ou conglomerados podem ser divididos em hierárquicos e não-hierárquicos. Os procedimentos hierárquicos (aqui empregados) geralmente partem de $N$ ' itens formando inicialmente (para a primeira junção ou primeiro estágio) $N^{\prime}-1$ conglomerados destes itens (um deles com 2 itens e $N^{\prime}-2$ com apenas um item), em um segundo estágio $N^{\prime}$-2 conglomerados destes itens, e assim por diante, até que um único conglomerado contendo todos os $\mathrm{N}^{\prime}$ itens seja formado, de modo aglomerativo. No decorrer do processo, após dois itens serem agrupados, eles não são mais separados. Tal procedimento assemelha-se à construção em forma de árvore, unindo primeiro os conglomerados com maior similaridade. Medidas de similaridade são utilizadas inicialmente como critério para a junção dos conglomerados. Estas medidas podem ser caracterizadas como medidas de distância ou também como medidas correlacionais. As medidas de distância são frequentemente utilizadas quando objetos ou indivíduos são agrupados (JOHNSON; WICHERN, 2007).

Quando o objetivo é agrupar variáveis, as medidas de similaridade geralmente empregadas são medidas correlacionais. Destas, a principal medida é a correlação, muito utilizada por ser de fácil interpretação. Sejam duas variáveis aleatórias $i$ e $j$, a correlação entre elas é denotada por $\rho_{i j}$ e calculada de forma usual. Utilizando-se como distâncias $d_{i j}=1-\rho_{i j}$, obtém-se menor distância (maior similaridade) quanto maior a correlação. Contudo, esta estatística não obedece a propriedades métricas, pois não satisfaz a propriedade de desigualdade triangular. Para tanto, uma transformação do coeficiente de correlação pode ser considerada. Definindo-se (REIS, 2001)(Equação 2):

$$
d_{i j}=\left[0,5\left(1-\rho_{i j}\right)\right]^{1 / 2}
$$

esta nova distância obtida obedece às propriedades métricas. Novamente, quanto maior a correlação, menor a distância, que varia entre 0 e 1 neste caso. Os conglomerados hierárquicos possuem vários métodos que determinam como as medidas de similaridade entre eles são definidas. Inicialmente, quando cada observação constitui um conglomerado, a distância entre conglomerados é simplesmente a distância entre os itens ou variáveis. Posteriormente, quando os itens vão sendo agrupados, uma regra de ligação se faz necessária para calcular a similaridade entre os agrupamentos, sendo que, em pelo menos um deles, há mais de um item (HAIR et al., 2005).

Uma regra de ligação frequentemente utilizada é denominada ligação simples (single linkage). Ela define como critério de ligação (semelhança) a menor distância 
entre dois itens quaisquer pertencentes a agrupamentos distintos. São calculadas as menores distâncias assim definidas entre todos os agrupamentos existentes, e a distância mínima destas apontará quais agrupamentos serão agregados. Outra regra de ligação é a ligação média (average linkage), em que são calculadas as médias de distâncias entre todos os itens de agrupamentos distintos, e a menor distância média obtida indica a junção a ser realizada. Ao contrário da regra anterior, esta não é afetada por valores extremos, a menor distância, considerando-se todos os itens dos agrupamentos.

$\mathrm{Na}$ análise hierárquica para variáveis, a matriz de correlação amostral, denotada por $\mathrm{R}$, tem fundamental importância, pois esta mede o nível de associação entre as variáveis e dá origem à matriz de distâncias, denotada por $\mathrm{D}$, observando-se que os elementos de $\mathrm{R}$ e $\mathrm{D}$ são ligados por meio da expressão $d_{i j}=1-\rho_{i j^{\prime}}$. Se as correlações (de R) representando as similaridades não forem significantes, este problema é transferido para suas respectivas distâncias (para D). As junções entre as variáveis são obtidas a partir de diferenças de similaridades, logo, as correlações devem ser estatisticamente distintas para que não sejam gerados grupos espúrios de variáveis. Devem-se, então, testar as hipóteses referentes à matriz de correlação $\rho$ (esta é a matriz de correlação populacional), contudo, como esta é desconhecida, deve-se utilizar a matriz de correlação amostral $\mathrm{R}$ para estimá-la. As hipóteses a serem testadas são definidas como (REIS, 2001) (Equação 3):

$$
H_{0}: \rho=\left[\begin{array}{cccc}
1 & \rho & \cdots & \rho \\
\rho & 1 & \cdots & \rho \\
\vdots & \vdots & \ddots & \vdots \\
\rho & \rho & \cdots & 1
\end{array}\right] \text { vs. } H_{1}: \rho \neq\left[\begin{array}{cccc}
1 & \rho & \cdots & \rho \\
\rho & 1 & \cdots & \rho \\
\vdots & \vdots & \ddots & \vdots \\
\rho & \rho & \cdots & 1
\end{array}\right]
$$

Inicialmente, deve-se testar a estrutura presente nos elementos fora da diagonal da matriz de correlação amostral R. Aplicando-se os dados coletados na amostra (seção 2), a matriz $\mathrm{R}$ para preço (P), localização (L), rapidez $(\mathrm{R})$, qualidade $(\mathrm{Q})$, variedade $(\mathrm{V})$, estacionamento (E) e outras $(\mathrm{O})$, é dada a seguir. Como resultado do teste, rejeita-se $H_{0}$ a um nível de significância $\alpha=0,005$ (deve-se lembrar que o tamanho amostral é grande, o que explica a precisão obtida). Desta forma, ainda que as correlações não sejam altas, existem diferenças significativas nos elementos da diagonal principal da matriz $\mathrm{R}$ e a análise de agrupamentos pode ser aplicada (Equação 4).

$\mathbf{R}=\left[\begin{array}{cccccccc}\mathrm{P} & \mathrm{L} & \mathrm{R} & \mathrm{Q} & \mathrm{V} & \mathrm{E} & \mathrm{O} \\ 1 & & & & & & & \\ 0,064 & 1 & & & & & \\ 0,061 & -0,101 & 1 & & & & \\ -0,094 & -0,131 & 0,333 & 1 & & & \\ 0,150 & 0,082 & 0,129 & -0,104 & 1 & & \\ -0,024 & -0,061 & 0,050 & 0,057 & -0,076 & 1 & \\ -0,184 & -0,184 & -0,038 & -0,214 & -0,133 & -0,002 & 1\end{array}\right]$

Para o agrupamento hierárquico, uma crítica é quanto à sua instabilidade quando uma primeira combinação de itens (ou variáveis) pode ter ocorrido com pequena diferença de critérios. Para tanto, aconselha-se uma divisão da amostra em pelo menos dois grupos, realizando-se o mesmo procedimento para verificar se são obtidos conglomerados similares.

A Figura 1, a seguir, representa as junções obtidas com seus níveis de similaridade, utilizando correlação simples (ou seja, utiliza-se simplesmente $\rho_{i j}$ ) e ligação média (é a junção obtida por meio da menor média de distâncias entre todos os agrupamentos distintos). Como exemplo, a primeira junção que foi realizada é rapidez com qualidade, pois seu nível de similaridade é dado por $1-0,333=0,667$ (ou equivalente a 66,7 na Figura 1 ), a que mais se aproxima de 1 (ou de 100 na Figura 1). Os níveis de distância são obtidos com os menores valores das matrizes de distância no decorrer do processo de agrupamento, sendo o nível inicial zero.

Para melhorar a análise de agrupamentos, pode-se proceder a uma comparação assumindo-se a ligação média como critério para todas as análises, visando-se evitar os problemas que podem ocorrer com a ligação simples, como comentado anteriormente. Também, foi utilizada uma divisão da amostra total em duas amostras, relativas à primeira semana de coleta (157 questionários, relativos aos dias 3, 4 e 5 - vide Tabela 1) e à segunda semana (146 questionários, relativos aos dias 10, 11 e 12). Nestas duas amostras, variou-se também o tipo de correlação, sendo aplicadas a correlação simples e a correlação transformada (expressão (2)) que obedece às propriedades métricas. Formando-se quatro cenários para a análise de agrupamentos, observou-se que houve poucas alterações nas junções e, quando estas ocorreram, foram em um nível de similaridade muito pequeno, portanto desconsideráveis. Na Figura 2, pode-se observar a situação dos agrupamentos com correlação transformada e ligação média. As Figuras 1 e 2 representam o que ocorre tipicamente com as divisões em duas amostras e dois tipos de correlação. Desta forma, pôde-se verificar a consistência da análise de agrupamentos final obtida.

Outra questão importante é relativa ao número de agrupamentos que a análise final deve suportar. Vários critérios foram elaborados, contudo nenhum deles pode garantir com absoluta certeza o número ótimo de agrupamentos. Neste trabalho, utilizou-se a análise fatorial, considerando-se a magnitude dos autovalores para cada uma das características de frequência dos clientes ao supermercado.

\subsection{Análise fatorial}

Nas Figuras 1 e 2, pôde-se observar que algumas junções ocorrem em um nível de similaridade muito baixo (partes superiores das figuras); estas junções não devem ser consideradas. Um critério bastante utilizado é 
realizar uma análise fatorial (AAKER et al., 2004) com o objetivo de redução do número de agrupamentos com pouca perda de representatividade. Isto é medido pelos autovalores, que são os escalares $\lambda_{1}, \lambda_{2}, \ldots, \lambda_{k}$ satisfazendo-se a equação polinomial $|\mathrm{R}-\lambda \mathrm{I}|=0$, na qual $\mathrm{R}$ é a matriz quadrada $k x k$ (de correlações amostrais) e I é a matriz identidade $k x k$. Seja $\lambda_{i}$ um autovalor de R, se $\mathrm{x}_{k x 1}$ é um vetor tal que $\mathrm{x}_{k x 1} \neq 0_{k x 1}$ (não é um vetor com elementos iguais a zero), e também $\mathrm{R}_{k x 1}=\lambda_{i} \mathrm{x}_{k x 1}$ então $\mathrm{x}_{k \times 1}$ é dito ser um autovetor da matriz $\mathrm{R}$ associado ao autovetor $\lambda_{i}$.

$\mathrm{Na}$ análise fatorial, os autovalores de cada eixo (ou fator) representam o quanto da variância amostral total (ou da informação total) neles ficou retida, ou seja, o quanto da variância original é explicado pelo seu respectivo fator. A variância total original, por sua vez, pode ser obtida somando-se todos os autovalores. Estes podem então ser somados do maior para o menor, até que se atinja um nível satisfatório de informação, desprezando-se os menores e, consequentemente, reduzindo-se os conglomerados e, possivelmente, obtendo-se uma estrutura mais fácil de ser explicada. Para se obterem os autovalores, pode ser utilizada tanto a matriz amostral de covariâncias, como a matriz amostral de correlações.

Utilizando-se a matriz amostral de correlações, obtém-se a Figura 3 (gráfico scree plot), que representa a análise fatorial utilizando-se, para as sete variáveis, seus autovalores ordenados em forma decrescente, de 1 a 7 no gráfico. Se cada variável tivesse o mesmo volume

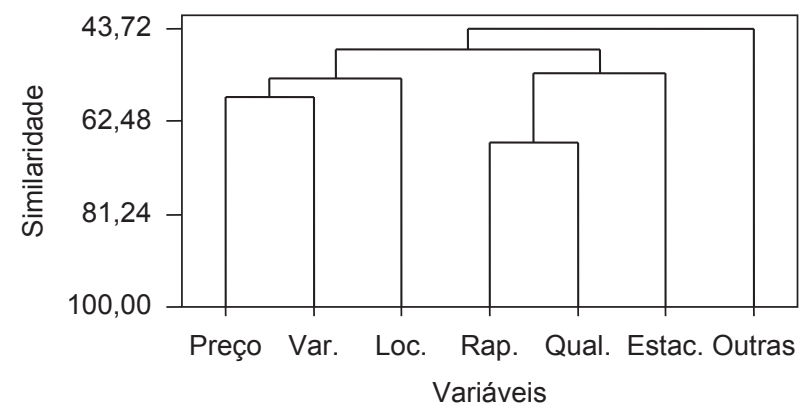

Figura 1. Representação gráfica dos agrupamentos utilizando-se correlação simples e ligação média para todos os questionários.

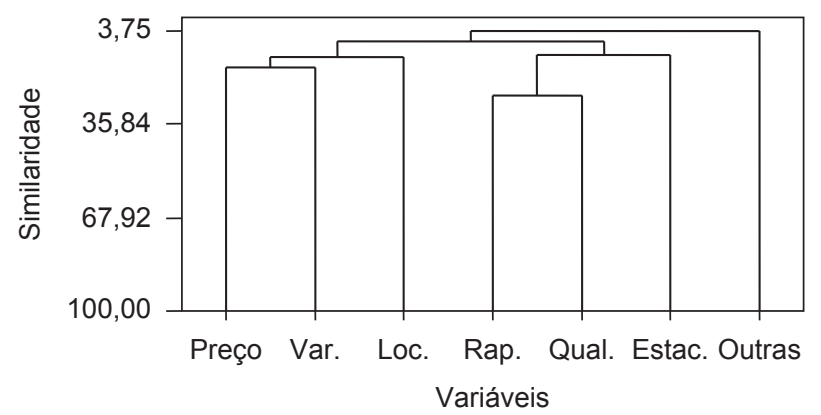

Figura 2. Representação gráfica dos agrupamentos utilizando-se correlação transformada e ligação média para todos os questionários. de informações (de variabilidade ou importância) todos os seus respectivos autovalores teriam valor igual a um. Contudo, observa-se que isto não ocorre e que a consideração de apenas três fatores pode ser satisfatória, pois há um grande decréscimo (queda no gráfico) a partir daí e, ainda, os fatores restantes têm autovalores menores que um, ou seja, têm pouca absorção de informação, podendo então ser descartados por ter menor importância. Também, acaba sendo corroborada a análise até então explicitada pelos resultados anteriores, ou seja, um agrupamento formado por preço, variedade e localização, outro agrupamento com rapidez, qualidade e estacionamento, e a variável outras de forma isolada, como propiciado pelos quatro cenários analisados anteriormente. Deve-se ressaltar ainda que não havia outra estrutura de agrupamentos concorrente a esta, já que as análises hierárquicas ficaram muito coerentes, ou seja, muito parecidas umas com as outras em suas junções.

De forma geral, pode-se notar que ficaram estabelecidos dois grupos bastante interessantes: no primeiro, rapidez, qualidade e estacionamento e, no segundo, preço, variedade e localização. Nota-se que o primeiro grupo privilegia atendimento, enquanto o segundo privilegia basicamente preço em mercadorias variadas, portanto, bastante distintos.

\subsection{Outras características dos clientes}

Neste estudo, algumas informações adicionais sobre os clientes foram analisadas (conforme seção 2.1), sendo que estas podem ser associadas conjuntamente. Uma informação é o número de itens que os clientes costumam comprar no supermercado. Uma forma de analisar os dados pode ser definindo classes em função do número de itens, por exemplo: classe A para quem adquire até 15 itens, $\mathrm{B}$ de 16 a 70 itens e $\mathrm{C}$ acima disto, conforme Figura 4. Observa-se na figura que a classe A contém dois terços dos clientes, enquanto a classe C contém

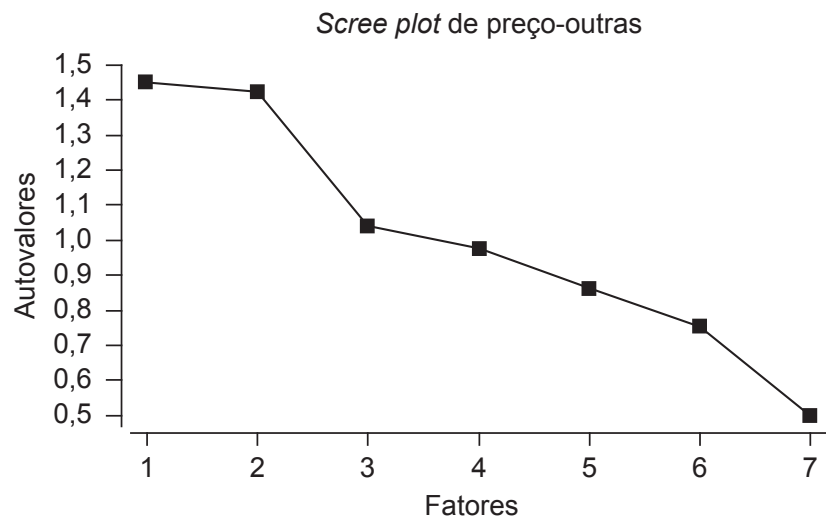

Figura 3. Scree plot dos autovalores para preço, variedade, rapidez, qualidade, localização, estacionamento e outras, utilizando-se análise fatorial, sem rotação e com matriz de correlação. 
apenas $11 \%$. Outra informação é a impressão do cliente em haver diferença de preços de produtos entre supermercados distintos. Dos entrevistados, 66,7\% disseram acreditar que isto ocorra (classe denotada por S), 29,7\% disseram não acreditar que isto ocorra $(\mathrm{N})$ e 3,6\% não sabiam responder (NS). No caso destes últimos, a razão apontada foi que não faziam compras em outros estabelecimentos, sendo fiéis ao supermercado analisado.

A escolaridade dos clientes é outra informação importante, pois está relacionada à renda e, consequentemente, ao poder de compra (como é visto posteriormente). Espera-se que, para diferentes níveis de escolaridade, haja comportamentos e necessidades distintas, portanto, quantificar esta informação, ainda que de forma amostral, pode ser relevante. Nos seis dias de coleta, foram entrevistados 307 clientes, sendo que foram utilizadas 303 respostas. Para evitar categorias com pouca representatividade, resolveu-se juntar os ensinos completos e incompletos, pois, para os incompletos, houve pouca frequência. Desta forma, as categorias se reduziram a: sem escolaridade (s/ escol.), ensino fundamental (Esc1), ensino médio (Esc2) e ensino superior (Esc3), cuja representação gráfica pode ser vista na Figura 5, a seguir. A próxima técnica estatística empregada analisa cruza-

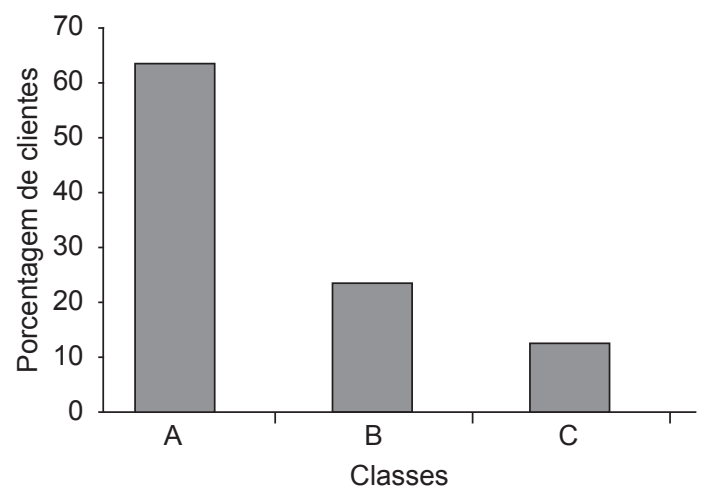

Figura 4. Representação gráfica das classes para o número de itens por cliente.

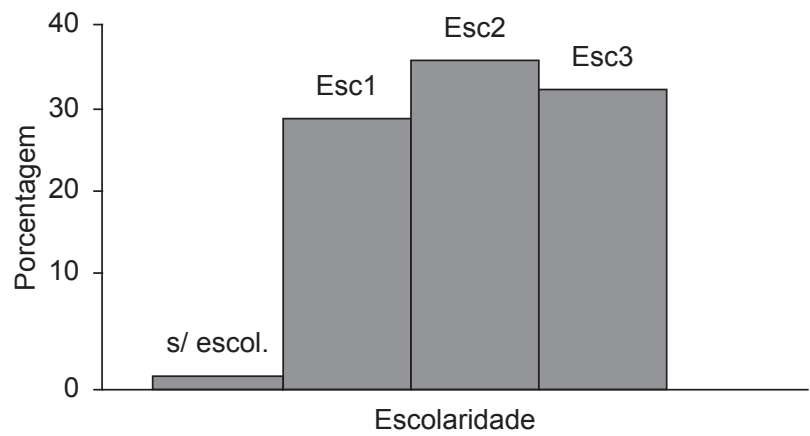

Figura 5. Representação gráfica para a junção dos diferentes níveis de escolaridade, para os dias de coleta. mentos entre estas informações dos clientes e as causas pelas quais eles afirmam frequentar o supermercado.

\section{Análise de correspondência}

\subsection{Análise de correspondência simples}

O principal objetivo da análise de correspondência é a representação de dados categóricos em um espaço de dimensão menor, identificando seus aspectos. As variáveis consideradas podem ser nominais e ordinais, com categorias mutuamente exclusivas ou não. Em uma tabela de frequências (ou de contagem) das variáveis analisadas, pode haver associações entre suas categorias. A análise de correspondência tem como produto final um gráfico no qual tais associações podem ser visualizadas. A análise de correspondência simples envolve uma tabela de dupla entrada, referente ao cruzamento de apenas duas variáveis. O gráfico apresenta dois conjuntos de pontos: $I$, pontos correspondendo às linhas, e $J$, pontos correspondendo às colunas. As associações podem ser obtidas por meio dos pontos (categorias) linha que estão próximos dos pontos (categorias) coluna, e que representam combinações que ocorrem com maior frequência do que seria esperado por um modelo de independência, ou seja, no qual as categorias linha não estariam correlacionadas com as categorias coluna. Como resultados da análise de correspondência simples, é obtida a melhor representação bidimensional dos dados e uma medida denominada inércia, que representa a quantidade de informação retida em cada dimensão.

Como exemplo, pode-se utilizar a característica preço (com sete categorias: P0, P2, ..., P7), realizando-se um cruzamento com a escolaridade (com três categorias: Esc1, Esc2, Esc3 - vide seção 3.3). As categorias para preço devem ser entendidas como, por exemplo, $\mathrm{P} 0$ sendo a categoria na qual os clientes não apontaram preço, P7, a categoria na qual os clientes apontaram preço em primeira ordem, P6, em segunda ordem, e assim sucessivamente. Este procedimento também é seguido para todas as outras características. A Tabela 3 de dupla entrada representa essa situação.

Analisando-se esta tabela, pode-se observar que a frequência com que os clientes apontaram preço como a primeira característica para frequentar o supermercado (categoria P7) decresce conforme a escolaridade aumenta. Por outro lado, a frequência com que os clientes que simplesmente não apontaram preço (categoria $\mathrm{P} 0$ ) cresce conforme a escolaridade aumenta. A análise de correspondência pode então ser utilizada na tentativa de estabelecer o quão próximas as categorias dessas variáveis se encontram, ou seja, permite avaliar de forma mais fidedigna se a suposta relação pode ser considerada como autêntica. $\mathrm{O}$ corpo da tabela dá origem à matriz $\mathrm{X}_{(I x J)}$ de frequências 
encontradas. Deve-se observar que, para a Tabela 3, $I=7$ categorias de preço e $J=3$ categorias de escolaridade. A partir de $\mathrm{X}_{(I x J)}$, é calculada a matriz de correspondência, denotada por $\mathrm{P}_{(I x J)}=\left\{p_{j}\right\}$ (também conhecida como matriz de proporções), obtida por $\mathbf{P}_{(I x J)}=\frac{1}{n} \mathbf{X}_{(I x J)}$. Esta matriz passa por um elaborado tratamento algébrico. Seja $r_{i}$ a soma da linha i para $i=1,2, \ldots, I$ e $c_{j}$ a soma da coluna $j$ para $\mathrm{j}=1,2, \ldots, J$. Para cada elemento da matriz $\mathbf{P}_{(I x J)}$ $\left(p_{i j}\right)$, é realizada a transformação $\frac{p_{i j}-r_{i} c_{j}}{\sqrt{r_{i} c_{j}}}$, para $i=1,2, \ldots$,
$I$ e $j=1,2, \ldots, J$.

A subtração efetuada corresponde à centralização de $\mathrm{P}_{(I x J)}$ e a divisão por $\sqrt{r_{i} c_{j}}$ corresponde à padronização de $\mathrm{P}_{(I x J)}$. Este processo origina uma nova matriz que é decomposta em um produto de três outras matrizes. Neste produto, a matriz do centro é formada pelos autovalores da nova matriz, denotada por $\Lambda_{(J-1) x(J-1)}$, sendo que $\Lambda_{(J-1) x(J-1)}=\operatorname{diag}\left(\lambda_{1}, \lambda_{2}, \ldots, \lambda_{J-1}\right)$, ou seja, é uma matriz diagonal formada pelos autovalores com $\lambda_{1}>\lambda_{2}>\ldots \lambda_{J-1}$. Por meio das matrizes fornecidas na decomposição da nova matriz, são obtidos também novos eixos (ou componentes) de coordenadas e as coordenadas para a melhor representação bidimensional dos dados.

Como uma última etapa, deve-se obter uma medida denominada inércia, de grande importância para avaliar a análise de correspondência resultante. A inércia total é uma medida de variação dos dados e pode ser definida por $\sum_{i=1}^{k} \lambda_{i}^{2}$, na qual $\lambda_{1} \geq \lambda_{2} \geq \ldots \lambda_{k}>0$ são os valores não nulos da diagonal de $\Lambda_{(J-1) x(J-1)}$. Desta forma, havendo $k$ autovalores não nulos, então, também, $k=\min (I-1, J-1)$. As inércias associadas a alguma dimensão são definidas como o quadrado dos valores singulares (dos autovalores) não nulos, ou seja, $\lambda_{i^{\prime}}^{2}$ Os valores de $\lambda_{\mathrm{i}}$ indicam (como é próprio de autovalores) quanta informação é retida em sua respectiva dimensão. É interessante observar a relação entre a medida usual de associação Qui-Quadrado

Tabela 3. Cruzamento entre as variáveis preço e escolaridade.

\begin{tabular}{lrrrr}
\hline \multicolumn{5}{c}{ Escolaridade } \\
\hline Preço & Esc1 & Esc2 & Esc3 & Total \\
\hline P0 & 40 & 58 & 65 & 163 \\
P2 & 0 & 0 & 1 & 1 \\
P3 & 12 & 14 & 9 & 35 \\
P4 & 3 & 3 & 8 & 14 \\
P5 & 4 & 8 & 6 & 18 \\
P6 & 7 & 9 & 9 & 25 \\
P7 & 25 & 19 & 3 & 47 \\
Total & 91 & 111 & 101 & 303 \\
\hline
\end{tabular}

(denotada simplesmente por $\chi^{2}$ ) para uma tabela de dupla entrada. Esta é dada por (Equação 5):

$$
\text { inércia total }=\sum_{i=1}^{I} \sum_{j=1}^{J} \frac{\left(p_{i j}-r_{i} c_{j}\right)^{2}}{r_{i} c_{j}}=\chi^{2} / n,
$$

na qual $\chi^{2}=\sum_{i, j} \frac{\left(O_{i j}-E_{i j}\right)^{2}}{E_{i j}}$, em que $O_{i j}$ é a frequência observada e $E_{i j}$ é a frequência esperada para $i j$-ésima célula da tabela de frequências.

As análises das características apresentadas a seguir foram consideradas para todos os 303 questionários (exceto quatro referentes à categoria sem escolaridade), em todos os dias de coleta. É retomada então a análise da característica preço associada à escolaridade, apresentando-se alguns resultados e o gráfico para interpretação das associações. Deve-se ressaltar que a dimensão restante após todos os cálculos da análise de correspondência é dada por $k=\min (I-1, J-1)$, isto é, podem existir muitas representações bidimensionais das quais a melhor (com menor perda de informação) é apresentada. Em se tratando do cruzamento com a escolaridade, para as características em questão, não há perda de informação, pois $J-1=2$, ou seja, $k=\min (I-1, J-1)=2$, ou seja, os dois novos eixos (ou componentes). Assim, o gráfico contém toda a informação dos dados. Esta situação vai ocorrer em outras análises realizadas nesta seção. Com estas considerações, o gráfico da análise de correspondência simples para a característica preço associada à escolaridade é apresentado na Figura 6, a seguir. Nesta, estão os novos eixos (componente 1 e componente 2 ) obtidos pela decomposição citada. Interpretando-se a Figura 6, pode-se dizer que a escolaridade 1 (Esc1) é a que mais se aproxima de P7, ou seja, para esta classe o preço deve ter grande importância nos motivos pelos quais frequenta o supermercado. Por outro lado, a escolaridade 3 (Esc3) se aproxima de P0 e P4, representando baixa importância para esta categoria, sendo ainda que escolaridade 2 (Esc2) está alocada em um plano intermediário (de transição). Desta forma, pode-se observar uma tendência inversa entre preço e escolaridade.

Uma característica bastante interessante de ser estudada é a rapidez de atendimento, pois pode haver muitas reclamações se o tempo de espera não for satisfatório. Pelo gráfico da rapidez (Figura 7, a seguir) nota-se alta prioridade (categorias R6 e R7) para escolaridade 3. A escolaridade 1 apresenta baixa prioridade, pois está próxima a R0 e R4, sendo que a escolaridade 2 novamente está em uma posição intermediária. Disposto isto, pode-se dizer que a prioridade de rapidez cresce conforme se aumenta escolaridade. Observe-se ainda o isolamento de cada categoria de escolaridade com as citadas categorias de rapidez, evidenciando-se a associação entre elas.

A característica qualidade, como foi visto, está diretamente ligada à rapidez. Observa-se na Figura 8, a seguir, que a categoria escolaridade 3 está próxima às categorias 
Q6, Q5 e Q7, ou seja, tem alta prioridade em qualidade. As categorias escolaridade 1 e escolaridade 2 estão mais próximas a $\mathrm{Q} 0$ e $\mathrm{Q} 4$, indicando baixa prioridade. Nota-se, ainda, que a escolaridade 3 está bem distanciada de escolaridade 1 e escolaridade 2, parecendo atrair as três categorias mais altas de qualidade, ou seja, as categorias Q5, Q6 e Q7. Para a característica localização,

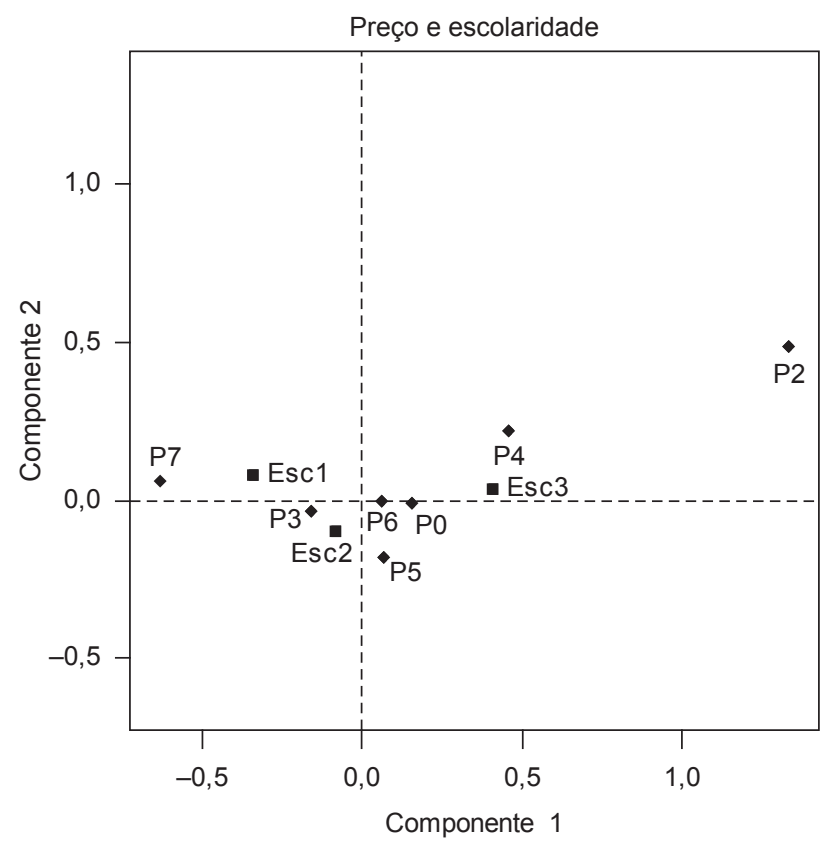

Figura 6. Análise de correspondência simples considerando-se preço e escolaridade.

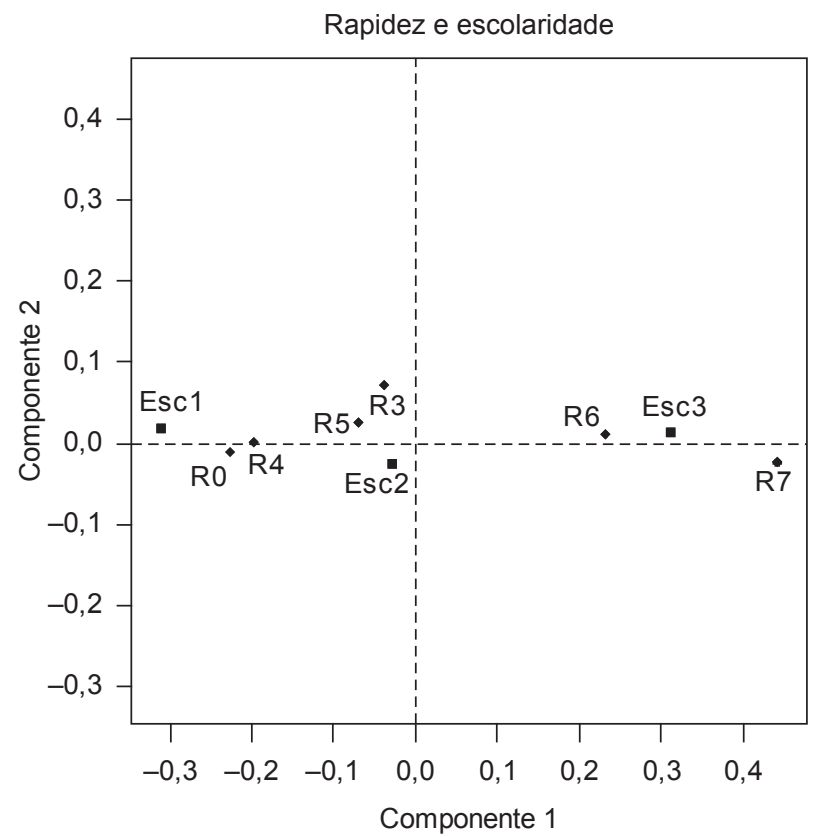

Figura 7. Análise de correspondência simples considerando-se rapidez e escolaridade. foi observado que existe uma tendência de aumento de prioridade conforme existe um aumento de escolaridade. Observou-se ainda um distanciamento entre as categorias de escolaridade, reforçando a diferença de comportamento. Já as características variedade, estacionamento e outras se mostraram muito dispersas e sem um comportamento que pudesse revelar alguma tendência consistente em relação à escolaridade.

Foi também realizada a análise da impressão do cliente quanto à diferença de preços entre supermercados distintos (classes S, N e NS - vide seção 3.3), associada à escolaridade do cliente. Analisando-se a Figura 9 a seguir, observa-se que a categoria escolaridade 1 está mais próxima da categoria $S$, enquanto a escolaridade 2 está mais próxima ao centro, em posição intermediária entre S e NS. Claramente, a escolaridade 3 está muito mais próxima a $\mathrm{N}$ e isolada das demais categorias, ou seja, esta categoria está associada a não haver diferenças de preços entre supermercados, ao contrário da escolaridade 1 .

Outra análise realizada foi a das classes relativas ao número de itens adquiridos por cliente, associada à escolaridade do cliente (classes A, B e C - vide seção 3.3). Analisando-se a Figura 10, a seguir, pode-se notar claramente que a escolaridade 1 está associada à categoria $\mathrm{B}$ (compras médias), pois se encontra bastante distante das demais e de forma bem isolada. Nota-se também que a escolaridade 2 está associada à categoria $\mathrm{A}$ (compras pequenas, até 15 itens), pois estão bem próximas. Finalmente, a escolaridade 3 é a que está mais próxima da isolada categoria $\mathrm{C}$ (compras grandes com mais de

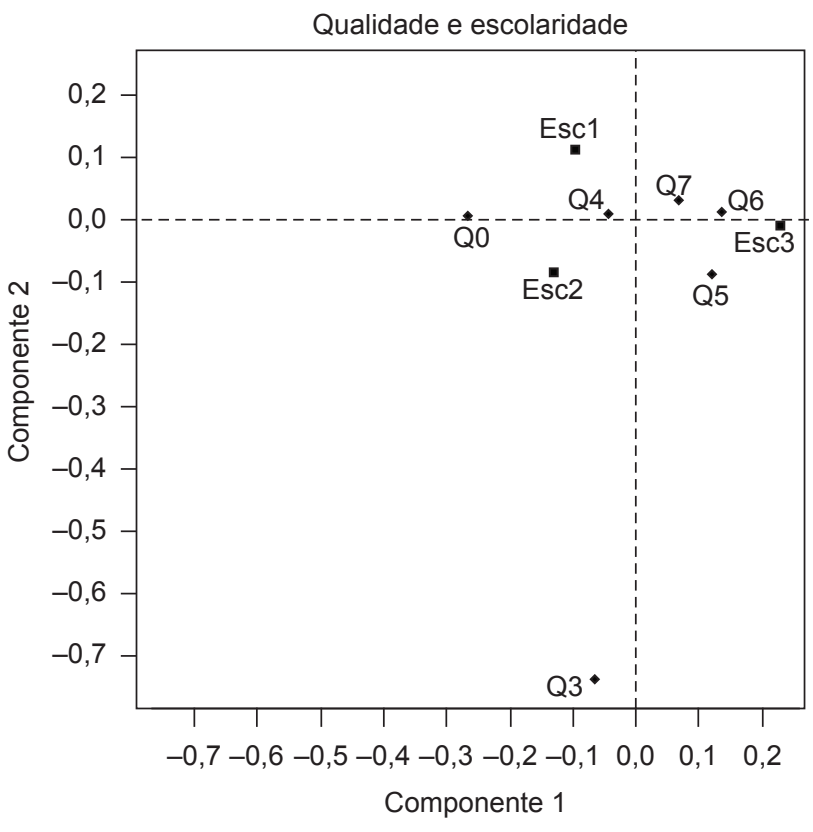

Figura 8. Análise de correspondência simples considerando-se qualidade e escolaridade. 


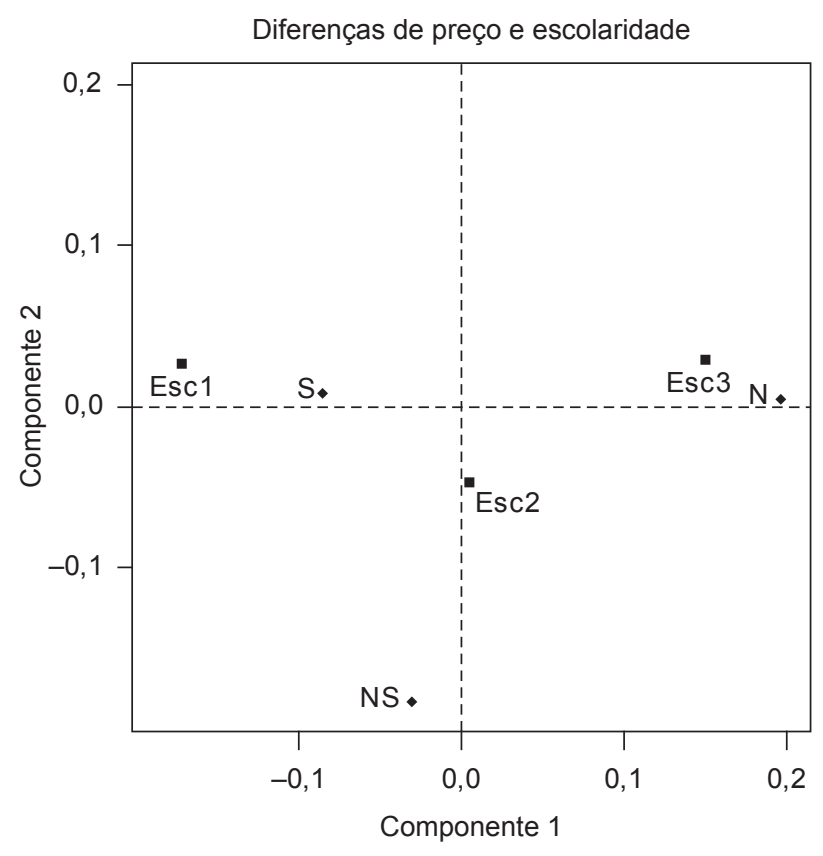

Figura 9. Análise de correspondência simples considerando-se diferença de preços e escolaridade.

70 itens), contudo, esta escolaridade parece se encontrar em uma posição intermediária entre as categorias A e C. Pode-se pensar, então, que a escolaridade 3 pode estar realizando compras cujo número de itens é relativo às duas classes em questão.

Todas as análises anteriores dão suporte e direcionamento a análises mais abrangentes. Desta forma, a análise de correspondência múltipla, na qual mais de duas variáveis são cruzadas, permite a associação de características como preço e variedade com escolaridade. Cruzamentos desse tipo podem ser obtidos ampliando o alcance dos resultados até aqui encontrados, tornando os resultados mais completos.

\subsection{Análise de correspondência múltipla}

A análise de correspondência múltipla é uma extensão da análise de correspondência simples para o caso de três ou mais variáveis categóricas. Este procedimento é muito parecido com o anterior; as variáveis com suas categorias são ajustadas em uma sequência de forma que fiquem todas no mesmo espaço multidimensional. Desta forma, a análise de correspondência múltipla realiza uma análise de correspondência simples na qual cada coluna da matriz corresponde a um nível da variável categórica. Anteriormente, uma tabela de dupla entrada era analisada, enquanto que aqui, uma tabela de múltiplas entradas é projetada dentro de uma dimensão.

O procedimento da análise de correspondência múltipla traz algumas alterações importantes para a análise dos dados. Nesta, utiliza-se apenas uma dimensão (ou uma variável), assim obtêm-se apenas contribuições para um

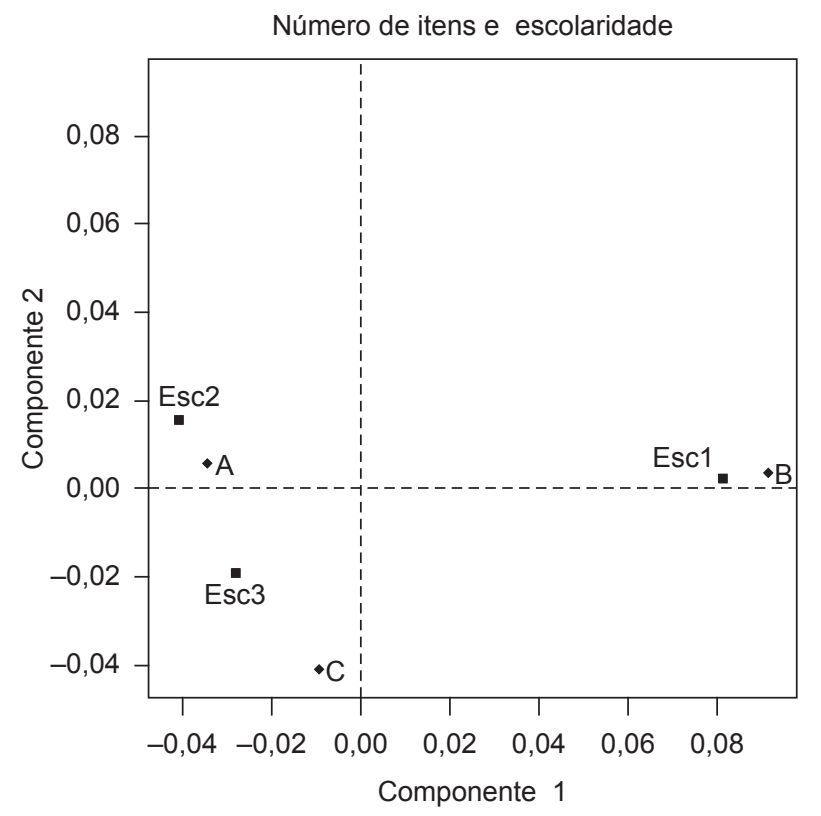

Figura 10. Análise de correspondência simples considerando-se as classes para o número de itens e escolaridade.

perfil, o das colunas. Contudo, não se pode desprezar da análise o número de categorias para cada uma das variáveis originais, ainda que, como se disse anteriormente, todas tenham sido alocadas como uma única variável. Então, se o número de categorias em cada bloco (das $j$ variáveis originais, por exemplo) de categorias são dados respectivamente por $C_{l}, C_{2}, \ldots, C_{j}$, o número total de dimensões é dado por (Equação 6):

$$
\sum_{i=1}^{j}\left(C_{i}-1\right)
$$

Da mesma forma como ocorria na análise de correspondência simples, a análise múltipla considera partições da estatística $\chi^{2}$. Assim sendo, o número de dimensões (eixos ou componentes) determina também o número de inércias (e de autovalores), tornando válida a mesma idéia sobre perda de informações citada anteriormente. Apesar da análise de correspondência múltipla se tornar uma poderosa ferramenta para analisar a associação de um grande número de variáveis, percebe-se pela expressão (3) que pode haver facilmente perda de informação. Existe então, uma relação direta entre esta perda e a dimensão desejada (geralmente pequena). Como exemplo, para melhor entendimento da técnica, é considerada a análise para as características preço e variedade, juntamente com escolaridade. Percebe-se pela expressão (3) que o número de dimensões (novos componentes gerados por autovalores decrescentes) é dado por $(7-1)+(7-1)+(3-1)=14$, lembrando que as categorias P1 e V1 têm frequência zero. 
A primeira análise realizada é para as características preço e variedade associadas à escolaridade. Observando-se a Figura 11 a seguir, nota-se que a escolaridade 3 está perto da categoria $\mathrm{P} 0$, como ocorreu para a análise de correspondência simples. Da mesma forma, a escolaridade 1 está perto das categorias P6, P5, P4 e P7, o que está condizente com a análise anterior, conforme a Figura 6. Para a característica variedade, a escolaridade 3 se encontra próxima da categoria V7. A escolaridade 2 fica em posição de indefinição, próxima ao centro do gráfico. Apesar da análise de correspondência múltipla apontar necessidade de muitos componentes, sua análise comparada às efetuadas com a análise de correspondência simples revela a não existência de conflito entre elas, ao contrário, parece existir grande concordância e similaridade nos resultados. Desta forma, pela coerência encontrada, pode-se considerar a validade do resultado obtido.

Outra análise realizada foi a das características rapidez, qualidade e escolaridade. Analisando-se a Figura 12, pode-se evidenciar que as escolaridades 1 e 2 têm baixa prioridade em qualidade e rapidez, acentuadamente para a categoria escolaridade 1. Este resultado está bastante coerente com as análises de correspondência simples, obtidas para rapidez e qualidade. Da mesma forma, esta coerência é mantida, observando-se que existe alta prioridade em rapidez e qualidade para a categoria escolaridade 3 . Um fato interessante é notado do lado direito da Figura 12, na qual as categorias Q6 e R7 se encontram no lado superior do gráfico, enquanto as categorias Q7 e R6 estão no lado inferior, se contrapondo. Este fato provavelmente ocorreu devido aos clientes com escolaridade 3 terem alternado suas respostas em qualidade

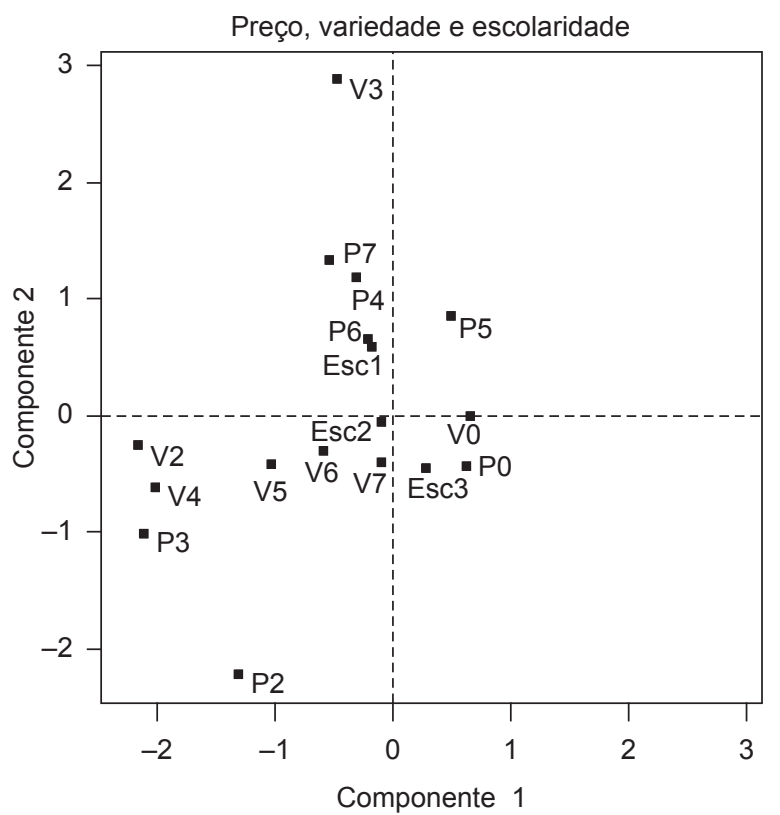

Figura 11. Análise de correspondência múltipla considerando-se preço, variedade e escolaridade. e rapidez entre a primeira e a segunda opção, aproximando Q6 com R7 e Q7 com R6. Ainda, em torno da categoria escolaridade 3, estão várias categorias de alta e média prioridade para rapidez e qualidade, como ocorria com as análises de correspondência simples.

A última análise apresentada é referente ao cruzamento das classes de itens e diferença de preços, associadas à escolaridade. Aqui, o número de componentes é $(3-1)+(3-1)+(3-1)=6$. Pela Figura 13, observa-se que clientes com escolaridade 3 estão associados com maiores compras (classe $\mathrm{C}$ ) e em não acreditar em diferença de preços $(\mathrm{N})$, e clientes com escolaridade 1 estão associados em acreditar em diferença de preços (S) e realizar compras médias (B). A escolaridade 2 está associada a compras pequenas (A) e tem uma posição intermediária em relação à diferença de preços.

Destas características apresentadas, muito já se apostou em preço, contudo, com a intensificação da disputa pelo cliente, cada vez mais informado e exigente, o preço, muito provavelmente, não é o único e nem o principal fator que determinará a preferência do cliente. Para mais detalhes do processo de coleta de dados da seção 2 e das análises das seções 3 e 4, o leitor pode consultar Rinaldi (2007).

\section{Conclusões}

Neste trabalho, estudaram-se algumas causas pelas quais clientes frequentam um supermercado, tais como: preço de produtos, localização do estabelecimento, rapidez de atendimento, qualidade de atendimento, varie-

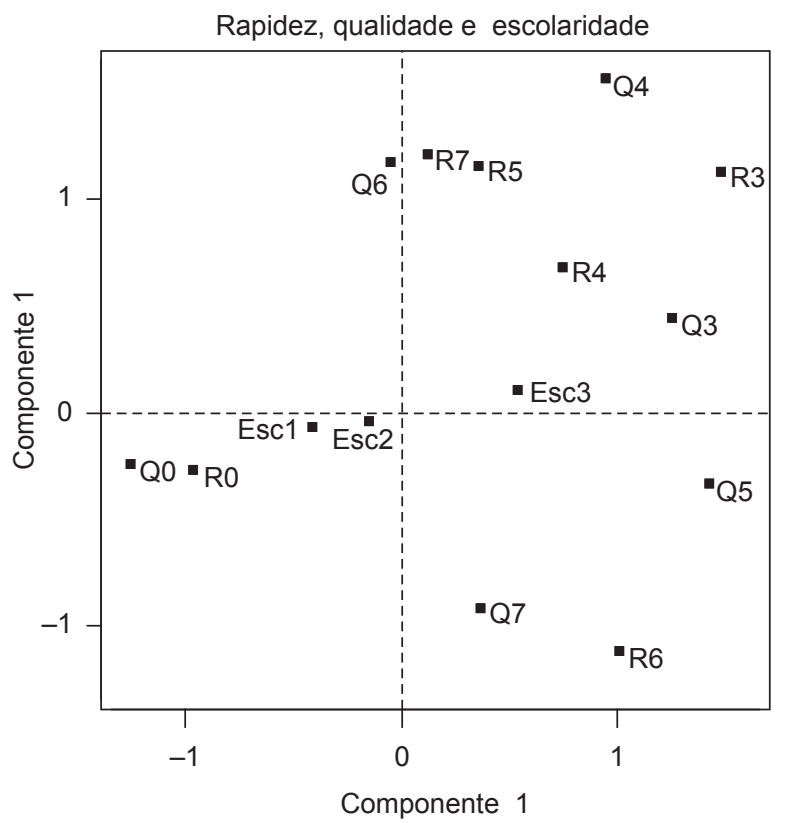

Figura 12. Análise de correspondência múltipla considerando-se rapidez, qualidade e escolaridade. 
dade de produtos, estacionamento e outras. Por meio de análise dos intervalos de confiança simultâneos, observou-se que a qualidade e rapidez de atendimento formam as características mais apontadas pelos clientes como motivo de frequência ao supermercado. Estas duas características estão significativamente superiores ao preço, na opinião dos clientes da empresa estudada.

A qualidade e rapidez de atendimento são características que estão associadas, segundo a análise de agrupamentos hierárquicos. De acordo com os dados coletados, estas características estão interligadas e pertencem a um conceito mais global, de satisfação com o atendimento recebido (Figura 14). Assim, se a rapidez de atendimento estiver afetada negativamente, isto será refletido na satisfação do

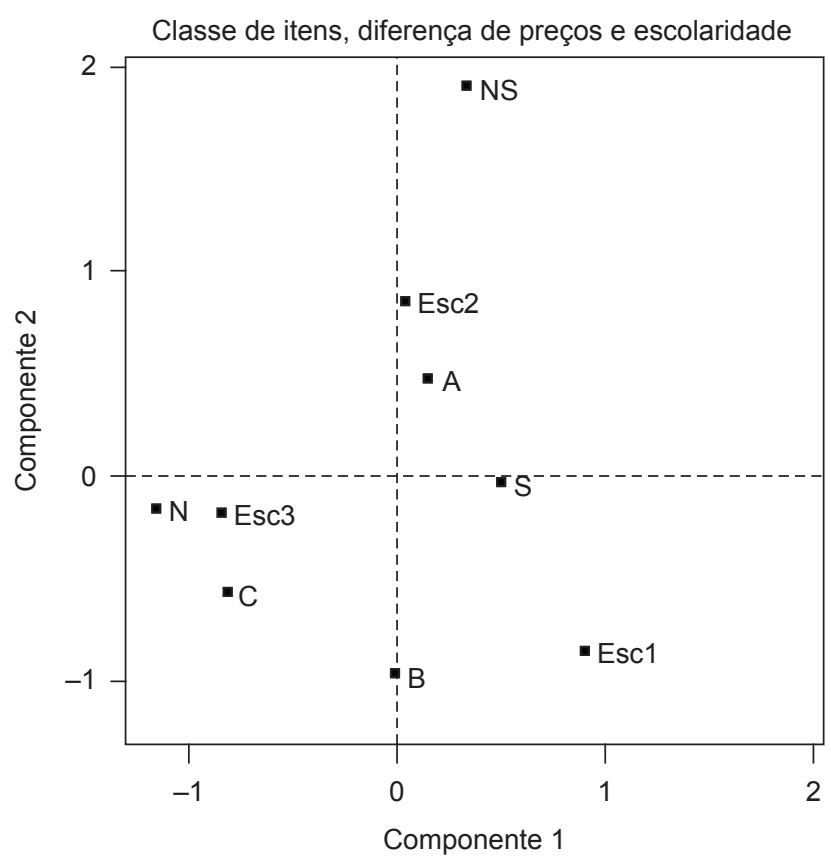

Figura 13. Análise de correspondência múltipla considerando-se classes de itens, diferença de preços e escolaridade. cliente, podendo, além disso, afetar sua percepção quanto à qualidade de atendimento recebida.

Os cruzamentos das características acima com a escolaridade dos clientes, por meio de análise de correspondência, permitem realizar algumas considerações. A característica preço está associada às escolaridades mais baixas, enquanto localização, rapidez e qualidade estão associadas a escolaridades mais altas. Cruzando-se rapidez, qualidade e escolaridade, pode-se perceber que escolaridades mais baixas têm pouca prioridade com relação a estas características, ao contrário de escolaridades mais elevadas.

Finalmente, o cruzamento de classes de número de itens comprados, percepção de diferença de preços entre supermercados e escolaridade dos clientes, permite considerar que clientes com escolaridades mais altas parecem efetuar compras com maior número de itens e não acreditar haver diferença de preços entre supermercados. Ao contrário, clientes com escolaridades mais baixas parecem realizar compras menores e acreditar haver diferença de preços. Isto se torna mais coerente quando é considerada a pesquisa da PNAD (pesquisa nacional por amostra de domicílio) do IBGE, que mostra que a renda média de um trabalhador brasileiro está diretamente ligada à sua escolaridade, ou seja, clientes com maior escolaridade tendem a ter rendas significativamente mais elevadas. Para estes clientes, não haver diferenças de preços entre supermercados deve ser interpretado como não haver diferença significativa de preços, o que é inerente ao seu poder aquisitivo. Além disso, efetuar compras possivelmente maiores também depende de sua possibilidade financeira.

Quando se pensa em rapidez de atendimento em supermercados, é inevitável relacioná-la ao tempo de fila. Pequenas esperas dentro do supermercado, enquanto se fazem compras, parecem bem suportadas pelos clientes. $\mathrm{O}$ que poderia afetar negativamente a rapidez de atendimento é um tempo de fila alto, no qual os clientes dificilmente se ocupam com alguma tarefa, dado que

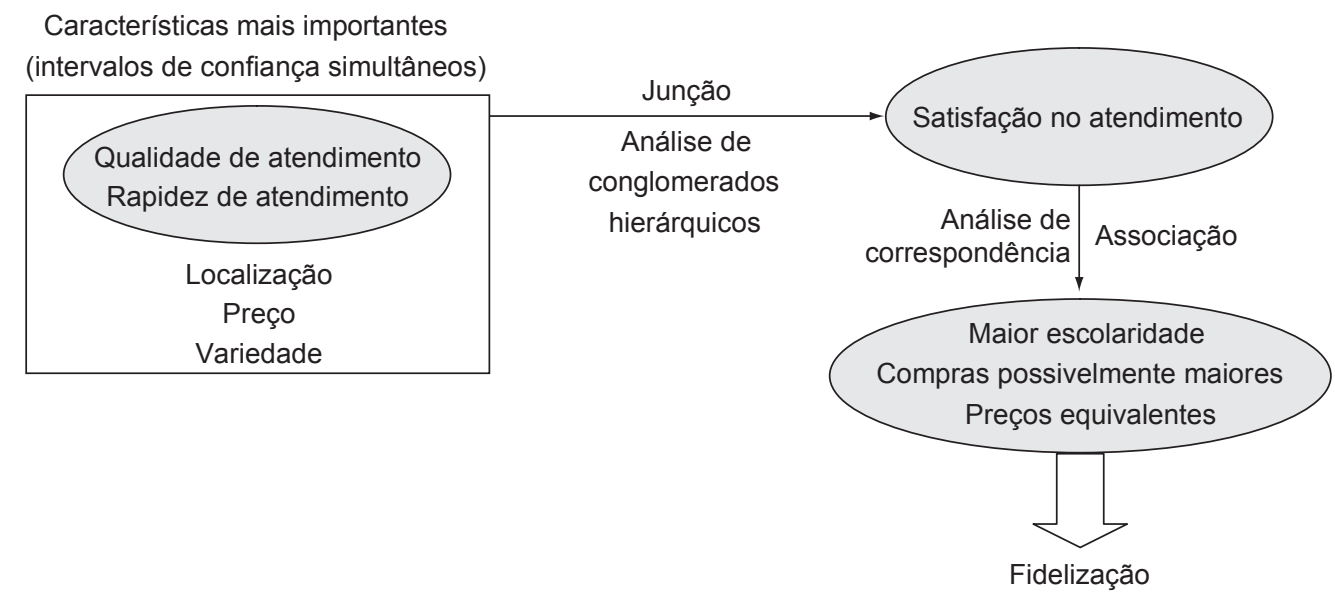

Figura 14. Esquema das análises e associações entre as características apontadas pelos clientes como motivo de frequência ao supermercado. 
suas compras terminaram. Uma vez modificada a rapidez de atendimento, pode-se, como consequência, afetar a possível fidelização de algumas categorias de clientes.

Desta forma, é possível que o principal atrativo para a frequência dos clientes nos supermercados, do ponto de vista dos clientes, não esteja nas prateleiras. Estes podem querer pagar por qualidade e rapidez no atendimento recebido. Desta forma, o preço pode não ter toda a importância que em geral lhe é atribuída, pelo menos é o que sugere a análise no supermercado pesquisado. Ainda, a satisfação ao atendimento recebido pode ser um fator determinante para a desejada fidelização, o que pode não ocorrer com preço.

Supermercados têm passado por algumas transformações, inclusive devido à tendência em haver grande diversidade de comportamentos de clientes. Desta forma, as empresas tendem a melhor conhecer sua clientela por meio de coleta de informações geradas nos pontos de venda (SANTOS; GIMENEZ, 2002). Realizar uma análise mais elaborada pode revelar comportamentos sobre os clientes que possam originar uma perspectiva mais ampla e segura para tomada de decisões.

Perspectivas de pesquisa futura podem ser consideradas. Parece ser importante relacionar-se escolaridade ao comportamento do cliente. Desta forma, considerando-se supermercados com clientes com menor grau de escolaridade que o estudado, pode-se analisar o impacto que esta mudança teria nas características estudadas, como em preço, por exemplo. Também, para se obter maior abrangência dos resultados para a pesquisa, outras variáveis com suas respectivas categorias podem ser incorporadas, como sexo e faixa etária. Obtendo-se resultados em outros locais e com novas variáveis, os resultados podem revelar tendências do comportamento do consumidor em relação ao atendimento prestado pelos supermercados.

\title{
The importance of quick responsiveness in supermarkets: a case study
}

\begin{abstract}
In this study we analyze some reasons by which customers go to supermarkets regularly such as: price of products, establishment location, quick responsiveness, quality of service, variety of products, parking lot, and others. Using multivariate statistical analysis, the relevance of each reason in contrast with others, and their relative importance were verified. As a result, it was observed that quick responsiveness has an important role compared to others for the customer service level. Through the hierarchical cluster and correspondence analysis, it was possible to associate reasons with groups and reasons with factors. The level of the customers' education was associated with the factors that lead them to go regularly to the place. This is an interesting observation since in Brazil there is a significant relationship between income and education. The study was carried out in a supermarket in Sao Paulo State; therefore, this is a case study thus presenting inferential limitations.
\end{abstract}

Keywords: Supermarkets. Quick responsiveness. Cluster analysis, Correspondence analysis.

\section{Referências bibliográficas}

AAKER, D. A.; KUMAR,V.; DAY, G. S. Pesquisa de marketing. Tradução Reynaldo Cavalheiro Marcondes. 2 ed. São Paulo: Atlas, 2004.

BADIN, N. T. Avaliação da produtividade de supermercados e seu benchmarking. Florianópolis, 1997. 130f. Dissertação (Mestrado em Engenharia de Produção) - Universidade Federal de Santa Catarina.

BARTHOLOMEW, D. J. et al. The analysis and interpretation of multivariate data for social scientists. Florida: Chapman \& Hall/CRC, 2002.

BRASIL. Comércio varejista: supermercados. In: BNDES: Banco Nacional de Desenvolvimento. Brasília, nov. 1996. Disponível em:<http://www.bndes.gov/conhecimento/relato/supermerca. pdf>. Acesso em: 11 Jul. 2006.
BOBBITT, L. M.; DABHOLKAR, P. A. Integrating attitudinal theories to understand and predict use of technology-based selfservice: the internet as an illustration. International Journal of Service Industry Management, v. 12, n. 5, p. 423-450, 2001.

CARVAlHO, H. Análise multivariada de dados qualitativos: utilização da HOMALS com o SPSS. Lisboa: Silabo, 2004.

COGAN, S. Gerenciando as percepções nas filas de espera: para aumentar o nível de satisfação dos clientes. Rio de Janeiro: Qualitymark, 1998.

DABHOLKAR, P. A.; BOBBITT, L. M.; LEE, E. J. Understanding consumer motivation and behavior related to self-scanning in retailing: implications for strategy and research on technologybased self-service. International Journal of Service Industry Management, v. 14, n. 1, p. 59-95, 2003. 
DABHOLKAR, P. A.; BAGOZZI, R. P. An attitudinal model of technology-based self-service: moderating effects of consumer traits and situational factors. Journal of the Academy of Marketing Science, v. 30, n. 3, p. 184-201, 2002.

GUERRA, S. Mais por menos: produtividade para resultados. Brasília: Associação dos analistas e profissionais de investimentos do mercado de capitais, jun. 2006. Disponível em: <www.apimecmg.com.br>. Acesso em: 11 Jul. 2006.

HAIR Jr., J. F. et al. Análise multivariada de dados. Tradução Adonai Schlup Sant'Anna e Anselmo Chaves Neto. 5 ed. Porto Alegre: Bookman, 2005.

ITTIG, P. T. The real cost of making customers wait. International Journal of Service Industry Management, v. 13, n. 3, p. 231-241, 2002.

JOHNSON, R. A.; WICHERN, D. W. Applied multivariate statistical analysis. 6 ed. New Jersey: Pratice Hall, 2007.
PEREIRA, J. C. R. Análise de dados qualitativos: estratégias metodológicas para as Ciências da Saúde, Humanas e Sociais. 3 ed. São Paulo: Edusp, 2004.

REA, L. M.; PARKER, R. A. Metodologia de pesquisa. São Paulo: Pioneira, 2000.

REIS, E. Estatística multivariada aplicada. 2 ed. Lisboa: Silabo, 2001.

RINALDI, J. G. S. A importância da rapidez de atendimento nos caixas de supermercados: um estudo de caso utilizando um modelo analítico de filas com trocas. São Carlos, 2007. 175f. Tese (Doutorado em Engenharia de Produção) - Universidade Federal de São Carlos.

SANTOS, A. M. M. M.; GIMENEZ, L. C. P. Reestruturação do comércio varejista e de supermercados. In: BNDES: Banco Nacional de Desenvolvimento. Brasília, jan. 2002. Disponível em <http://www.bndes.gov.br/conhecimento/bnset/set903.pdf >. Acesso em: 15 Jan. 2008.

\section{Anexo}

Questionário aplicado para coleta de dados:

Ordenar quais as características mais importantes pelas quais frequenta este supermercado:

( ) preço dos produtos

( ) localização do supermercado

( ) rapidez no atendimento dos caixas (tempo de fila, etc.)

( ) qualidade de atendimento nos caixas (cortesia, etc.)

( ) variedade de mercadorias no supermercado

( ) estacionamento

( ) outras:

Escolaridade do entrevistado

Número de itens comprados:

Você $(\mathrm{Sr}, \mathrm{Sra}, . .$.$) acredita que para uma compra exista diferença significativa de preços entre supermercados$ distintos?

\section{Sobre os autores}

\section{José Gilberto Spasiani Rinaldi}

Departamento de Matemática, Estatística e Computação,

Faculdade de Ciências e Tecnologia - FCT, Universidade Estadual Paulista - Unesp,

Rua Roberto Simonsen, 305, CEP19060-900, Presidente Prudente, SP,

e-mail: gilberto@fct.unesp.br

\section{Reinaldo Morabito}

Departamento de Engenharia de Produção,

Universidade Federal de São Carlos - UFSCar,

Rodovia Washington Luiz, km 235, CEP 13565-905, São Carlos, SP,

e-mail: morabito@ufscar.br

\section{Vilma Mayumi Tachibana}

Departamento de Matemática, Estatística e Computação,

Faculdade de Ciências e Tecnologia - FCT, Universidade Estadual Paulista - Unesp,

R. Roberto Simonsen, 305, CEP19060-900, Presidente Prudente, SP,

e-mail: vilma@fct.unesp.br

Agradecimentos: Os autores agradecem aos revisores anônimos os úteis comentários e sugestões. 